\title{
Urethral adenocarcinoma with bilateral iliac and inguinal lymph nodes which revelead by urethra ectropion in a 67-year-old woman: A case report
}

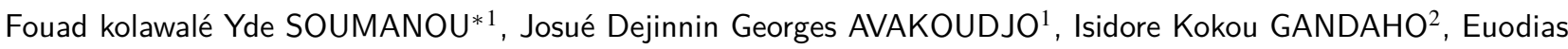 \\ DJENGUE ${ }^{3}$ \\ ${ }^{1}$ Department of Urology, University Hospital of Cotonou, Benin \\ ${ }^{2}$ Department of Urology, University hospital of Parakou, Benin \\ ${ }^{3}$ Department of gynecologist- obstetrist of abomey-calavi hospital, Benin
}

Received: April 9, 2018

DOI: $10.5430 /$ crcp.v5n $1 \mathrm{p} 8$

\author{
Accepted: May 1, 2018 \\ Online Published: May 10, 2018
}

\begin{abstract}
We reported a case of urethral adenocarcinoma in a 67-year-old woman who was admitted for difficulty voiding, irritative voiding symptoms, bloody urethral discharge and urinary incontinence. Physical examination was realised by gyneacologist and conclued to urological pathology. Urological examination was showed urethral ectropion which was bleeding. She had no fewer, no pelvic pain even less loss weight. Her general state was satisfactory. The lymph nodes of right side inguinal were felt. Computed imaging was showed involvement of right side bladder and bilateral iliac inguinal lymph nodes. Urethral ectropion biopsy anatomopathological screening was conclued to clear cell adenocarcinoma but CIS lesions were not found. The tumor staging was T3N2M0. A radiotherapy was perfomed. The patient was improvement of voiding symptoms and decrease lymph nodes size. Primary urethral carcinomas are rare pathology especially in the woman. Several histological types exist. However, chemotherapy and radiotherapy are very effective on very advanced stages. This cancer may be revealed by an urethral ectropion in a year-old woman.
\end{abstract}

Key Words: Ectropion, Urethra, Adenocarcinoma, Radiotherapy

\section{INTRODUCTION}

Primary urethral carcinomas (PUCs) are rare and account for less than $1 \%$ of genitourinary cancers. ${ }^{[1,2]}$ Most of the data rely on studies with small numbers of patients or case reports. The incidence of PUCs is known to be 3 to 4 times more common in the women than in the men. ${ }^{[3]}$ Urethral carcinoma can be encountered in the settings of primary urethral cancer, synchronous presentation with other genitourinary (GU) malignancies, relapse following primary urethral cancer, or metachronous recurrence after treatment of other GU malig- nancies. ${ }^{[4]}$ Most PUCs are localized; however, 30\% to $40 \%$ of patients present with regional lymph nodes metastasis. Although surgery and radiation treatment are options for early stage or distal urethral disease, advanced-stage and proximal PUC require multimodal treatment to optimize survival. ${ }^{[5]}$

\section{Clinical observation}

A 67-year-old woman was admitted for difficulty voiding, irritative voiding symptoms, bloody urethral discharge and urinary incontinence. The symptoms were started lasting

\footnotetext{
${ }^{*}$ Correspondence: Fouad kolawalé Yde SOUMANOU; Email: soumfou@yahoo.fr; Address: Department of Urology, University Hospital of Cotonou, Benin.
} 
since 5 years. She had no medical and surgical past history. She had no fewer, no pelvic pain and even less loss weight. Her general state was satisfactory. Physical examination has been were realised by gyneacologist and conclued to urological pathology. Urological examination was showed urethral ectropion (see Figure 1) which was bleeding. The lymph nodes of right side inguinal were felt.

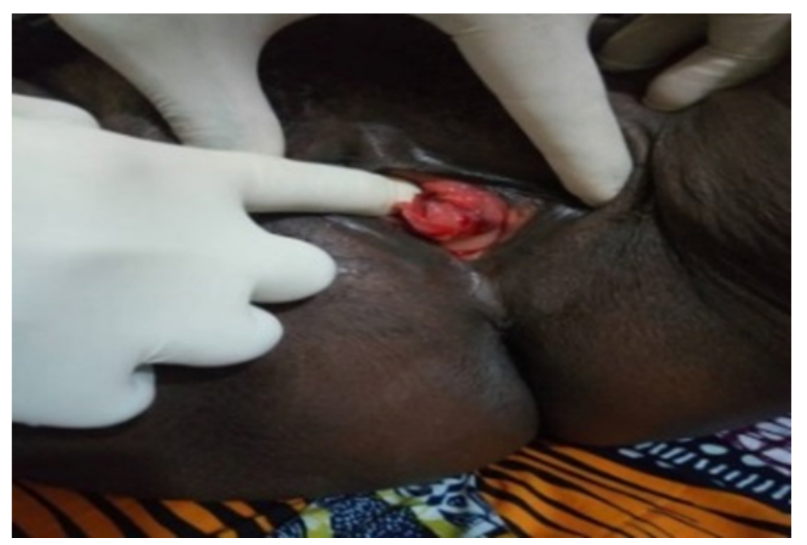

Figure 1. Urethral Ectropion

Urine culture identified Escherichia coli sensible to cephalosporins and aminoglycosides. Urethral ectropion biopsy anatomopathological screening was conclued to clear cell adenocarcinoma. CIS lesions were not found.

Computed imaging revealed: urethral cancer with involvement of the right side bladder; and bilateral iliac inguinal lymph nodes which size were betwen [15-31] mm with right side necrotic center. Column and rectum and uterine were healtly (see Figure 2).

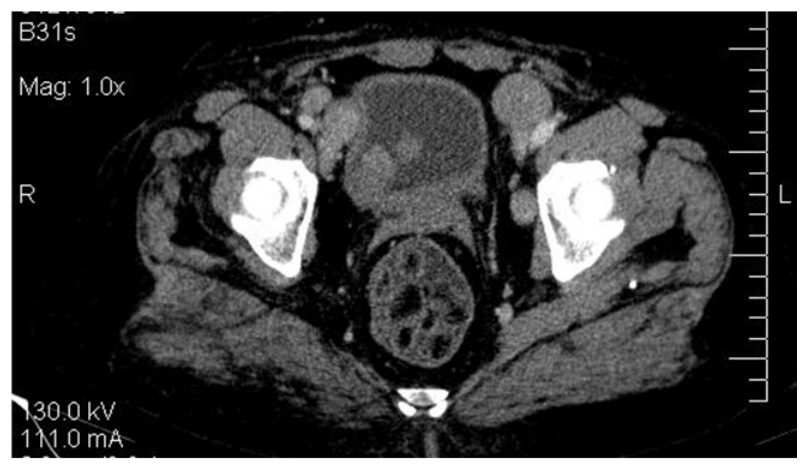

Figure 2. Involvement of the right side bladder + bilateral iliac then inguinal lymph nodes

This tumor staging was T3N2M0. The patient was referred to the radiotherapist.

We saw her 6 months and year later after cure. We were noticed improvement of the voiding symptoms and decrease Published by Sciedu Press of lymph nodes size. However, she could not make again the computed imaging.

\section{Discussion}

PUCs is exceeding rare, accounting for less than ${ }^{[6,7]} 1 \%$ of all malignancies. The incidence of PUCs increases with age, peaking in the greater than 75-year age group, and is more common in the African Americans. ${ }^{\text {[7] }}$ The risk factors for developing PUCs differ between men man and woman. ${ }^{[8,9]}$ Risk factors for man include urethral stricture, chronic irritation from intermittent catheterization, prior radiation therapy, and sexually transmitted disease (human papilloma virus serotype 16). This is in contrast to woman, whose risk factors for developing PUCs include following: the urethral diverticulum, chronic irritation and infection with human papilloma virus, and recurrent urinary tract infections. ${ }^{[10,11]}$ Females have a slightly different incidence of tumor type. Although urothelial cancers are the most common, occurring in $45 \%$ of cases, adenocarcinoma is more prevalent than SCC, occurring respectively in $29 \%$ and $19 \%$ of cases. ${ }^{[12]}$ The anatomic considerations have treatment implications because of the varied lymphatic drainage of the urethra. In women, the distal two-thirds drain into the superficial and deep inguinal lymph nodes, whereas the proximal third of the urethra drains into the pelvic lymph nodes. ${ }^{[13]}$ This explains in this study presence of bilateral inguinal and iliac lymph nodes. All urethra (proxiamal and distal) is reached.

Complete staging of patients with PUCs requires imaging with either MRI or computed tomography of the chest, abdomen, and pelvis. MRI may be the preferred study because of its ability to accurately stage locoregional disease and distant metastases, and response to chemoradiation therapy. ${ }^{[14]}$ A recent multi-institutional study confirmed these findings, demonstrating that $93 \%$ of clinically positive nodes on MRI were pathologically positive. ${ }^{[15]}$

But in this study computed tomography has was perfomed and showed bilateral inguinal and iliac lymph nodes with involvement of right side bladder. However, the most important prognostic indicators as it relates to survival are clinical stage (presence of nodal metastasis) and location of the primary tumor (proximal vs. distal). ${ }^{[15,16]}$ The tumor had invaded the entire urethra in this case. Treatment of male and female urethral cancer has historically been with surgical excision. ${ }^{[5]}$ Attempts to preserve the urethra in the setting of more advanced disease recurrence (T2-3), may result in suboptimal oncological control, with a relatively high risk for local recurrence approaching $20 \%$, even in patients treated for T2 disease in the primary setting. Overall, urethral preservation when there is recurrent, locally advanced disease is challenging. More extensive disease necessitates 
cystectomy with wide excision of the urethra, followed by urinary diversion. ${ }^{[17]}$

The prognosis of urethral tumors in woman depends on the size, stage, and anatomic location patient comorbidities, the type of diversion, as well as the presence or absence of systemic disease. ${ }^{[1,4,18,19]}$ Large tumor size is associated with poor prognosis. According to most studies, the women treated with radiation therapy for distal PUCs seem to have similar survival outcomes compared with those treated with surgery. ${ }^{[20]}$ In woman, radiotherapy is associated with less morbidity compared with surgery. Resection of the distal third of the urethra with adequate surgical margins has an increased risk of sphincteric injury. For low-stage tumors, radiation therapy as single modality seems to be effective for distal PUC. ${ }^{[21,22]}$

The utilization of mainly single modality radiation therapy has also been described in female patients with primary urothelial, squamous and adenocarcinoma of the urethra. The radiation treatment has involved external beam radiation alone, brachytherapy alone, or a combination of radiation modalities, utilizing 40 to 106 Gy of radiation. Selected patients have also received radiation to the regional lymph nodes. Reported local recurrence rates are $35 \%$ with this approach. ${ }^{[4]}$ Multimodal therapy is commonly used for posterior PUCs or advanced PUCs to improve outcomes. Combination therapies have also been reported, however, for distal tumors of the female urethra. Licht and colleagues report a case of stage T3NOM0 SCC (Squamous Cell Carcinoma) of the distal urethra where the patient was treated with a combination of chemoradiotherapy consisting of 5-FU (fluoroucacil) and mitomycin $\mathrm{C}$ with EBRT and remained disease free at 43 months. ${ }^{[23]}$

There are recent data demonstrating that contemporary platinum-based chemotherapy regimens are beneficial in the management of primary urethral cancers. Combination chemotherapy and radiation might also be applicable in patients with recurrent urethral tumors. In a retrospective study of 44 patients with primary urethral carcinoma (39\% squamous cell, $30 \%$ adenocarcinoma, $19 \%$ urothelial, $18 \%$ mixed/other; 98\% T3-T4, 43\% N1, and 16\% M1), a $72 \%$ pathologic response rate to neoadjuvant chemotherapy was observed. Patients who underwent surgery after chemotherapy had significantly improved overall survival compared with those who were managed with chemotherapy alone. ${ }^{[4]}$

\section{Conclusion}

Primary urethral carcinomas are rare pathology especially in the woman. Several histological types exist. However, chemotherapy and radiotherapy are very effective on very advanced stages. This malignant tumor can be expressed by an urethral ectropion in year old woman.

\section{CONFlicts OF INTEREST Disclosure}

No conflicts of interest.

\section{REFERENCES}

[1] Dalbagni G, Zhang ZF, Lacombe L, et al. Female urethral carcinoma: an analysis of treatment outcome and a plea for a standardized management strategy. Br J Urol. 1998; 82: 835. https: //doi.org/10.1046/j.1464-410X.1998.00878.x

[2] Dalbagni G, Zhang ZF, Lacombe L, et al. Male urethral carcinoma: analysis of treatment outcome. Urology. 1999; 53: 1126. https : //doi.org/10.1016/S0090-4295(98)00659-1

[3] Traboulsi SL, Witjes JA, Kassouf W. Contemporary management of Primary Distal Urethral Cancer. Urol Clin N Am. 2016; 43: $493-$ 503. PMid:27717435. https ://doi.org/10.1016/j.ucl. 2016 .06 .010

[4] Kamran ZS, Sexton WJ, Poch MA. Management of urethral recurrences urothelial and nonurothelial. Urol Clin N Am. 2016; 43: 51552. PMid:27717437.

[5] Zinman LN, Vanni AJ. Management of proximal primary urethral cancer should multidisciplinary therapy Be the Gold Standard? Urol Clin N Am. 2016; 43: 505-513. PMid:27717436.

[6] Gatta G, van der Zwan JM, Casali PG, et al. Rare cancers are not so rare: the rare cancer burden in Europe. Eur J Cancer. 2011; 47: 2493-511. PMid:22033323. https ://doi.org/10.1016/j.ejca .2011 .08 .008
[7] Swartz MA, Porter MP, Lin DW, et al. Incidence of primary urethral carcinoma in the United States. Urology. 2006; 68: 1164-8. PMid:17141838. https ://doi.org/10.1016/j.urology . 2006 .08 .1057

[8] Medina Perez M, Valero Puerta J, Sanchez Gonzalez M, et al. Squamous carcinoma of the male urethra, its presentation as a scrotal abscess. Arch Esp Urol. 1999; 52: 792-4 [in Spanish].

[9] Wiener JS, Liu ET, Walther PJ. Oncogenic human papillomavirus type 16 is associated with squamous cell cancer of the male urethra. Cancer Res. 1992; 52: 5018-23.

[10] Ahmed K, Dasgupta R, Vats A, et al. Urethral diverticular carcinoma: an overview of current trends in diagnosis and management. Int Urol Nephrol. 2010; 42: 331-41. PMid:19649767. https : //doi.org/10.1007/s11255-009-9618-x

[11] Libby B, Chao D, Schneider BF. Non-surgical treatment of primary female urethral cancer. Rare Tumors. 2010; 2: e55.

[12] Derksen JW, Visser O, de la Riviere GB, et al. Primary urethral carcinoma in females: an epidemiologic study on demographical factors, histological types, tumour stage and survival. World J Urol. 2013; 31: 147-53. PMid:22614443. https://doi .org/10.1007/s003 45-012-0882-5

[13] Carroll PR, Dixon CM. Surgical anatomy of the male and female urethra. Urol Clin North Am. 1992; 19: 339-46. 
[14] Gourtsoyianni S, Hudolin T, Sala E, et al. MRI at the completion of chemoradiotherapy can accurately evaluate the extent of disease in women with advanced urethral carcinoma undergoing anterior pelvic exenteration. Clin Radiol. 2011; 66: 1072-8. PMid:21839430. https://doi.org/10.1016/j.crad.2011.07.039

[15] Gakis G, Morgan TM, Efstathiou JA, et al. Prognostic factors and outcomes in primary urethral cancer: results from the international collaboration on primary urethral carcinoma. World J Urol. 2016; 34: 97-103. PMid:25981402. https://doi.org/10.1007/s003 45-015-1583-7

[16] Rabbani F. Prognostic factors in male urethral cancer. Cancer. 2011; 117: 2426-34. PMid:24048790. https://doi.org/10.1002/cn cr. 25787

[17] Dimarco DS, Dimarco CS, Zincke H, et al. Surgical treatment for local control of female urethral carcinoma. Urol Oncol. 2004; 22: 404-9. https://doi .org/10.1016/S1078-1439(03) 00174-1

[18] Bracken RB, Johnson DE, Miller LS, et al. Primary carcinoma of the female urethra. J Urol. 1976; 116: 188. https://doi.org/10.1
016/S0022-5347(17) 58741-8

[19] Narayan P, Konety B. Surgical treatment of female urethral carcinoma. Urol Clin North Am. 1992; 19: 373.

[20] Koontz BF, Lee WR. Carcinoma of the urethra: radiation oncology. Urol Clin North Am. 2010; 37: 459. PMid:20674700. https : //doi.org/10.1016/j.ucl.2010.04.007

[21] Johnson DE, O'Connell JR. Primary carcinoma of female urethra Urology. 1983; 21: 42. https://doi.org/10.1016/0090-429 5 (83) $90120-6$

[22] Moinuddin Ali M, Klein FA, Hazra TA. Primary female urethral carcinoma. A retrospective comparison of different treatment techniques. Cancer. 1988; 62: 54. https://doi.org/10.1002/1097-014 2(19880701)62:1<54: :AID-CNCR2820620112>3. 0. C0; $2-5$

[23] Licht MR, Klein EA, Bukowski R, et al. Combination radiation and chemotherapy for the treatment of squamous cell carcinoma of the male and female urethra. J Urol. 1918; 153: 1995. 